\title{
The Discussion of Communicative Language Teaching Approach in Language
} Classrooms

\author{
Luis Miguel Dos Santos
}

Woosong Language Institute, Woosong University, Daejeon, South Korea. Email:luismigueldossantos@yahoo.com

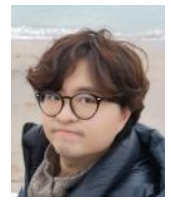

\begin{abstract}
Teaching language with effective theories, directions and ways of instructing is a vital topic in the current fields of teaching and learning. Locating the most appropriate and effective teaching and learning methodologies and strategies for a given situation is important for language learning classrooms. Over the years, many theories have been created to meet the needs of the learners of that time period. However, due to the rapid development of social and cultural environments, a large number of contemporary theories have been developed and employed in a variety of different approaches and applications. This paper is a literature review paper which discusses the Communicative Language Teaching (CLT) approach, together with relevant teaching and learning methodologies and strategies. The purpose of this paper is to outline advantages, disadvantages and applications of CLT. The researcher reviewed some historical and some current papers relating to how a CLT approach can be beneficial in the current classroom environment. The result of this paper was provision of an effective overview which applies to language teachers to assist in locating and establishing appropriate teaching and learning strategies for their students with different social and cultural backgrounds.
\end{abstract}

Keywords: Communicative language teaching; English language learning, Foreign language learning, Language teaching; Peer learning, Teachers' professional development, Teaching and learning strategy; Visual-only teaching strategy.

Citation | Luis Miguel Dos Santos (2020). The Discussion of Communicative Language Teaching Approach in Language Classrooms. Journal of Education and e-Learning Research, 7(2): 104-109.

History:

Received: 17 January 2020

Revised: 26 February 2020

Accepted: 30 March 2020

Published: 14 April 2020

Licensed: This work is licensed under a Creative Commons

Attribution 3.0 License $($ (c) $)$ E

Publisher: Asian Online Journal Publishing Group
Funding: This study received support from Woosong University Academic Research Funding 2020.

Competing Interests: The author declares that there are no conflicts of interests regarding the publication of this paper.

Transparency: The author confirms that the manuscript is an honest, accurate and transparent account of the study as reported, that no vital accurate and transparent account of the study as reported, that no vital
features of the study have been omitted and that any discrepancies from the features of the study have been omited
study as planned have been explained.

study as planned have been explained.
Ethical: This study follows all ethical practices during writing.

\section{Contents}

1. Introduction 


\section{Contribution of this paper to the literature}

This paper contributes to the fields of language teaching and learning, teaching methodologies and strategies and teachers' professional development.

\section{Introduction}

Internationally, language teaching and learning are two of the most important subject matters and instructions in contemporary school environments. Over the centuries, a large number of teaching and learning theories and strategies have been developed to meet the needs of different learners, target languages, geographic regions and student backgrounds. Nevertheless, the Communicative Language Teaching (CLT) approach is one of the most important and applicable teaching and learning theories in the contemporary language teaching profession (Savignon, 1987; Savignon., 2002). Since the late 1970s to early 1980s, the CLT approach has been advocated as an effective teaching and learning strategy. Although many teachers in the foreign language teaching profession try to employ the CLT approach to their classroom environments as much as possible, many teachers still do not understand how to manage and apply the approach appropriately for their students (Dos Santos, 2016a, 2017b).

In fact, the CLT approach may connect to different classroom activities and tools, such as discussion (Dos Santos, 2017b), group sharing (Alrashidi \& Phan, 2015), problem-based learning (Da Silva Cintra \& Bittencourt, 2015) and even role-play learning (Tweedie \& Johnson, 2018). However, some researchers (Taguchi, Magid, \& Papi, 2009) argue how teachers can develop and design curriculums and syllabuses that can merge the CLT approach. For example, the CLT approach is a methodology for discussion and role-play activities. But, can the CLT approach exist alone as an activity or teaching and learning tool? This article outlines a brief discussion about the CLT approach, the advantages of the approach, the disadvantages of the approach, and the application in the current language classroom environment.

\subsection{The Communicative Language Teaching Approach}

CLT is an approach rather than a theory (Savignon, 1987; Savignon, 2002). Unlike traditional theories, the Com CLT approach provides a large range of flexibilities and opportunities which both teachers and learners can exercise from time to time (Kennedy, 2002). The CLT approach is not solely a western phenomenon, but also a "universal effort that has found inspiration and direction in the interaction of initiative, both theoretical and applied, in many different contexts" (Savignon, 1987; Savignon, 2002). During the late 1960s and early 1970s, a large number of language teachers believed the traditional concepts of language learning were unable to respond to the demands of students (Baugh, 1993; Emerson, 1971). For example, many advocated that learning social terms, interpersonal and intercultural interactions were as important as learning grammar and vocabulary (Howatt \& Widdowson, 2004). In addition, language learning does not only mean training and language skills but also concentrating on the ability to communicate. In other words, the communicative approach is at the core of the teaching process, the process of communication (Krashen, 1982).

A large number of definitions of communicative competence have appeared in applied linguistics literature. Dell Hymes' works about communicative competence would be considered as one of the milestones of this knowledge (Hymes, 1967; Hymes., 1971; Hymes, 1972). Hymes considered this term to refer to what a learner needs to know so that they can successfully use a language in a given language group (Hymes, 1972). Hymes was reacting to another well-known language scholar (Chomsky, 1965) who had distinguished between competence and performance. Chomsky further explained competence as the theoretical linguistic ability of an ideal native speaker, while performance is this competence affected by other factors such as tiredness, social context, memory lapses and distractions (Chomsky, 1965; Chomsky, 1984; Chomsky, 1993). Hymes criticised this view as too idealised and limited. He thought that along with linguistics ability, communication and culture needed to be taken into account (Hymes, 1996).

Scholar (Hymes, 1996) believed that communicative competence could be defined in four categories, namely:

- Language skill - knowledge about language symbols such as syntax, voice, word formation rules, vocabulary etc.

- Social language skill - excellent abilities to handle four skills in the daily life environment.

- Textual competence - where speakers can handle both grammatical forms and context into a meaningful structure in both oral and written formats and text unity can be completed by language convergence and semantic coherence.

- Strategic competence - the skill to improve communication effectiveness or to avoid possible mistakes, both in verbal and nonverbal areas.

The core principle of the CLT approach is to learn in the language and to learn to use the language, but not learn the knowledge of the language (Savignon, 1987; Savignon, 2002). In other words, the purpose of the CLT approach is to help students handle the communication skills of the target language.

Traditionally, the Grammar-Translation Method and the Direct Method served as the basis of foreign language teaching-learning theories (Baugh, 1993; Emerson, 1971; Howatt \& Widdowson, 2004). These teaching and learning methodologies and strategies told us that teaching and learning languages are about how voice, grammar, and vocabulary could be delivered and directed with instructions to listen, speak, read and write (Wagner, Torgesen, \& Rashotte, 1994). However, these teaching and learning methodologies and strategies do not strongly focus on the communication and interaction between learners in practice (Dos Santos, 2019a). Therefore, with the enhancement and development of teaching and learning methodologies and strategies in the fields of language learning, since the last century, the CLT approach has been widely used in many language learning environments (Savignon, 2002). Gradually, the CLT approach took over from Grammar Translation Method and Direct Method, which had been very popular in the 1800 s and early 1900 s (Richards \& Rodgers, 2001).

Currently, in Western societies, the CLT approach tends to be a student-centred concept rather than a teachercentred concept. The responsibility of the teacher in the classroom is to lead the communication between students via the effective learning task. Usually, students are allowed to have interpersonal interaction, to share and 
exchange peer examinations and share contributions between each other. For example, in order to increase the opportunities for language speaking and sharing, many CLT advocators tend to employ role-play activities (Tweedie \& Johnson, 2018), presentations between groups and classmates (Dimond-Bayir, Russell, Blackwell, \& Flores, 2017), problem-based learning (Da Silva Cintra \& Bittencourt, 2015; San-Valero et al, 2019) technologicalassisted strategies and visual-only video teaching strategies (Dos Santos, 2019a; Dos Santos, 2019b), which allow students, classmates, peers, and even teachers to merge into the teaching and learning environment.

The CLT approach consistently encourages both teachers and students to seek teaching and learning materials and tools from their current living communities, environments and societies. For example, two recent studies (Dos Santos, 2019a; Dos Santos, 2019b) indicated that teachers could create visual-based teaching and learning materials using the students' communities as the source. Related material from communities, such as city halls, school buildings, mayors, shopping halls and school residential dormitories are some of the interesting and up-to-date teaching and learning materials which allow students to share and chat about their daily lives with their classmates.

Beyond the teaching and learning materials from the students' living communities and societies, the researcher (Dos Santos, 2019a; Dos Santos, 2019b) also advocated that if teachers can create social media-based discussion groups and chatting platforms for students to practice reading, speaking and writing skills, students are more likely to share their feedback and tasks with others, particularly in East Asian teaching and learning environments (Han, 2017). Moreover, students are encouraged to avoid speaking their native language in order to fully participate in the learning environment. During the exercise, students were asked to try their best to use English as their primary language. Language errors could be found during the talking. Teachers would then introduce any possible phrases, sentence structures or grammar etc after the exercise.

Nevertheless, there are a large number of teaching and learning methodologies and strategies in the contemporary educational database. Although each method and strategy have their own advantages and disadvantages, no single theory can be appropriate to all teaching and learning environments, classrooms, communities, schools, geographic regions, peoples, backgrounds, languages, perspectives, purposes or even nationalities. Therefore, in order to meet the expectations and needs of each individual classroom and student group, teachers and school leaders should always try and develop the most appropriate teaching and learning methodology and strategy for their students. In fact, even in the same school or university, the purpose of each individual classroom can be different. For example, English for Specific Purpose (ESP) students and English for Academic Purpose (EAP) students will have different backgrounds, purposes and expectations. Therefore, without any appropriate arrangement and management, students could not meet their goals or gain knowledge from their classroom.

\section{Overview of the Communicative Language Teaching Approach}

In general, only a few teachers concentrate on only one of the four skills in their language learning classrooms. Most English teachers expect their language learners to develop their communicative competence in reading, speaking, listening and writing skills as the comprehensive outcomes and performances after completing the language modules.

However, different skills may appear to be more relevant for specific learners. For example, different learners have different demands for language skills. International graduate students may have the desire to develop their writing and speaking skills due to the high-demand of project writing and thesis pressures (Sottie, MfoafoM'Carthy, \& Moasun, 2018). On the other hand, pre-school learners may tend to focus on general skills for overall and comprehensive language development.

English teachers should focus on different aspects of communicative competence at different times, as student communication needs are unlikely to remain the same throughout a longer course. In fact, a large number of language teaching and learning courses and modules tend to focus on one particular skill, such as CV writing. Thus, some branches of language courses were developed to satisfy particular demands, such as English for Academic Purpose (EAP), English for Specific Purpose (ESP), English for Business Purpose (EBP) and English for Nursing Students etc. Although many different branches and factors have been developed during the last few decades, the CLT approach may be applicable to most of the demands in language teaching and learning classrooms.

\subsection{Advantages}

Like many traditional and contemporary theories and approaches within the fields of language teaching and learning, the CLT approach offers a significant set of advantages for both teachers and students to enjoy the progress of learning (Harmer, 1988; Savignon, 2002). Below are some of the possible advantages.

Firstly, unlike the Grammar-Translation Method and the Direct Method (Baugh, 1993; Emerson, 1971; Howatt \& Widdowson, 2004) the CLT approach tends to be a student-centred and situation-oriented language teaching practice (Da Silva Cintra \& Bittencourt, 2015; Dos Santos, 2019a; Dos Santos, 2019b; San-Valero et al, 2019). Within the situation practices, teachers tend to develop some related activities within student living communities and societies. With these clear and familiar backgrounds and with understanding of the vocabulary and application of the sentences, students are more likely to share their thinking with their peers. Also, the situational practices in speaking may not have a strong focus on grammar and sentence translation accuracy. However, with these approaches, students may increase their understanding and knowledge of language use, feasibility and communication abilities.

Secondly, one of the other significant advantages of the CLT approach is the interaction between teachers, students and peers. For the CLT approach, the relationships between both peers and teachers are significantly increased and highly considered (Savignon, 2002). The CLT approach allows both teachers and students to transfer their traditional teaching and learning beliefs into an innovative teaching and learning approach. For example, a well-known educator (Dos Santos, 2019a; Dos Santos, 2019b) in language learning advocated that today's students like to use technological-assisted materials and tools for language learning, such as social media platforms and 
internet chat groups. In order to meet the needs of these students, such visual and interpersonal communicative tools must be created and employed.

Thirdly, the CLT approach usually increases the overall teaching and learning interests of students. Unlike the Grammar-Translation Method (Howatt \& Widdowson, 2004) students were the sole listeners of the lectures. Also, when students are allowed to participate in some real-life stories and exercises, this could develop the interests of the students beyond the classroom environment. Also, the related stories, exercises, problem-based materials and case studies are more closely related to daily activities. In other words, students became the protagonists instead of the audiences. Moreover, related activities do not only work in the classroom but also allow students to bring classroom activities into applications and the workplace after completion of the lessons (Jiménez, García, \& Pearson, 1996; Liao \& Yang, 2012).

\subsection{Disadvantages of Communicative Language Teaching Approach}

The Communicative Language Teaching approach provides a great number of advantages for teachers and learners to participate in effective language learning environments. However, some possible obstacles may serve as disadvantages within the teaching and learning environment. The following section indicates some of the possible obstacles.

Firstly, lack of language proficiency. In fact, some teachers may be unable to answer detailed question about the target language, sociolinguistics or culture as they arise from interactions in the classroom. The CLT approach encourages teachers to employ related teaching and learning materials and tools from living communities and societies (Dos Santos, 2019a). However, the range of these related materials could be large. Therefore, even if teachers prepared the lessons, some questions and challenges could be missed.

Secondly, in some countries, the CLT approach has been widely employed in many of their language learning classrooms. In the United States, for example, international students from all over the world, including students from both Eastern societies and Western communities, may be assigned into language learning environments and classrooms. However, due to the variety of social and cultural perspectives and backgrounds, many of these students tend to believe that traditional teaching and learning strategies (e.g. Direct Method, teacher-centred) are the only effective ways of teaching and learning. In other words, these students tend to focus their interests on memorising vocabulary and grammar. For a large number of students, traditionally, learning a new language is about memorising vocabulary and intensive reading of materials after completing each lecture. Therefore, many students are unwilling to fully accept the CLT approach due to their traditional views of language learning techniques (Ahn \& Kang, 2017; Lee \& Lee, 2019).

Thirdly, the pressures and requirements of standard examination guidelines may also influence the application and employment of the CLT approach. For example, in the United States, secondary school students are recommended to take the Scholastic Assessment Test (SAT) as one of the university entrance requirements. Such university entrance exams are also widely employed in many international locations and schools, such as the ALevel, and the General Certificate of Education (GCE). It is worth noting that many of these university entrance examinations do not require any type of oral language proficiency. Therefore, learners may not have any strong interest in participating in additional communicative training due to the requirement of these examinations.

Fourthly, learner behaviour would be highly influenced by the practice of the CLT approach in a classroom environment (Archambault, Vandenbossche-Makombo, \& Fraser, 2017; Baker, Grant, \& Morlock, 2008; Dos Santos, 2018). Unlike students in Western societies, learners from Eastern countries are not as motivated as other students even in the same classroom due to their social and cultural perspectives and practices (Ahn \& Kang, 2017; DeWaelsche, 2015; Kim, 2017; Lee \& Lee, 2019). For example, East Asian students tend to be passive learners due to their cultural background. In many circumstances, East Asian students defer any arguments to their peers and teachers due to the social and cultural respectfulness to their teachers, even if they made mistakes. Therefore, based on learner behaviour, the CLT approach may have potential limitations to some groups of learners due to social and cultural backgrounds and perspectives.

Fifthly, classroom size and student enrolment numbers for each individual classroom significantly influence the outcomes and performances of the CLT approach. In some circumstances, language learning courses could enrol more than 50 students in a large sized lecture hall. Such large sized lectures offer no opportunities for students to interact and communicate with their peers, as in a silent and concentrated environment. Also, teachers can usually not handle additional demands, questions, improvements or corrections for each individual student (Weiner, 2012; Weiner. \& Jerome, 2016).

Sixthly, psycho-linguists and social-linguists advocate that regardless of the age, gender, nationality or background of language learners, awareness of grammar acquisition and understanding of the language grammar, both systematic and progressive, is that it would be carried out in a certain order (Vygotsky, 1978, 1981). When teaching grammar with the CLT approach, teachers tend to create a situation which outlines ideas in a specific context in order to seek communicative functions, such as questions, ordering etc. (Dos Santos, 2019a; Dos Santos, 2019b; Vygotsky, 1981). Under this direction, the syntax of the systematic and progressive is subject to a certain degree of neglect, and can give people a disorderly understanding (Pratt, 1992; Wagner et al., 1994).

\section{Conclusion and Implementation}

The results of this paper suggest that although many teaching and learning methodologies and strategies are available for teachers to handle and arrange their classroom environments, teachers should always employ the appropriate teaching and learning methodologies and strategies based on the needs and expectations of their students. In fact, international students from different parts of the world are attending overseas colleges and universities due to the rapid development of globalisation. In previous decades, most university students tended to attend one of the colleges or universities in Western societies, such as British and American universities. However, due to the development and growth in Eastern societies, it is not uncommon for international students to attend colleges and universities in East Asian regions and communities. 
This paper also discussed and gathered some significant and important facts about the inclusion of the CLT approach in theory and practical management. Unlike traditional teaching and learning methodologies and strategies, such as the Direct Method, the current CLT approach encourages students to share and speak up about their ideas with peers and teachers without any limitations. From the last few decades to many contemporary studies and research projects, it is worth noting that the application of the CLT approach is very often employed in many theories and practices as the main comprehensive training method.

For future implementation, although the English language continues to serve as one of the best known foreign languages for these university students, many students may study basic to advanced level targeted language in their hosted colleges and universities. Therefore, language teachers should always consider how to employ the appropriate teaching and learning methodologies and strategies to these groups of international students with different social and cultural backgrounds.

\section{References}

Ahn, S.-Y., \& Kang, H.-S. (2017). South Korean university students' perceptions of different English varieties and their contribution to the learning of English as a foreign language. Journal of Multilingual and Multicultural Development, 38(8), 712-725.Available at: https://doi.org/10.1080/01434632.2016.1242595.

Alrashidi, O., \& Phan, H. (2015). Education context and English teaching and learning in the Kingdom of Saudi Arabia: An overview. English Language Teaching, 8(5), 33-44.Available at: https://doi.org/10.5539/elt.v8n5p33.

Archambault, I., Vandenbossche-Makombo, J., \& Fraser, S. L. (2017). Students' oppositional behaviors and engagement in school: The differential role of the student-teacher relationship. Journal of Child and Family Studies, 26(6), 1702-1712.Available at: https://doi.org/10.1007/s10826-017-0691-y.

Baker, J. A., Grant, S., \& Morlock, L. (2008). The teacher-student relationship as a developmental context for children with internalizing or externalizing behavior problems. School Psychology Quarterly, 23(1), 3-15.Available at: https://doi.org/10.1037/1045-3830.23.1.3.

Baugh, A. (1993). A history of the English language. Englewood Cliffs, N.J: Prentice-Hall.

Chomsky, N. (1965). Aspects of the theory of syntax. Cambridge, MA: Massachusetts Institute of Technology Press.

Chomsky, N. (1984). Modular approaches to the study of the mind. San Diego, CA: State University Press.

Chomsky, N. (1993). Language and thought. Wakefield, RI: Moyer Bell.

Da Silva Cintra, C., \& Bittencourt, R. A. (2015). Being a PBL teacher in computer engineering: An interpretative phenomenological analysis. Paper presented at the 2015 IEEE Frontiers in Education Conference (FIE)

DeWaelsche, S. A. (2015). Critical thinking, questioning and student engagement in Korean university English courses. Linguistics and Education, 32, 131-147.Available at: https://doi.org/10.1016/j.linged.2015.10.003.

Dimond-Bayir, S., Russell, K., Blackwell, A., \& Flores, C. (2017). Prism level 1 student's book with online workbook listening and speaking. Cambridge, UK: Cambridge University Press.

Dos Santos, L. M. (2016a). Foreign language teachers' professional development through peer observation programme. English Language Teaching, 9(10), 39-46.Available at: https://doi.org/10.5539/elt.v9n10p39.

Dos Santos, L. M. (2017b). How do teachers make sense of peer observation professional development in an Urban School. International Education Studies, 10 (1), 255-265.Available at: https://doi.org/10.5539/ies.v10n1p255.

Dos Santos, L. M. (2018). The cultural cognitive development of personal beliefs and classroom behaviours of adult language instructors: A qualitative inquiry. Brain Sciences, 8(12), 1-15.Available at: https://doi.org/10.3390/brainsci8120220.

Dos Santos, L. M. (2019a). English language learning for engineering students: Application of a visual-only video teaching strategy. Global Journal of Engineering Education, 21(1), 37-44.

Dos Santos.., L. M. (2019b). Science lessons for non-science university undergraduate students: An application of visual-only video teaching strategy. Journal of Engineering and Applied Sciences, 14(1), 308-311.Available at: https://doi.org/10.36478/jeasci.2019.308.311.

Emerson, O. (1971). The history of the English language. Ann Arbor, M.I: Plutarch Press.

Han, C. M. (2017). Individualism, collectivism, and consumer animosity in emerging Asia: Evidence from Korea. Journal of Consumer Marketing, 34(4), 359-370.

Harmer, J. (1988). The practice of English language teaching. Essex, UK: Pearson.

Howatt, A., \& Widdowson, H. G. (2004). A history of English language teaching (2nd ed.). Oxford, UK: Oxford University Press.

Hymes, D. (1967). Models of the interaction of language and social setting. Journal of Social Issues, 23(2), 8-28.Available at: https://doi.org/10.1111/j.1540-4560.1967.tbo0572.x.

Hymes, D. (1971). Pidginization and creolization of languages. London, UK: Cambridge University Press.

Hymes, D. (1972). On communicative competence. In Sociolinguistics (pp. 269-293). London, UK: Penguin.

Hymes, D. (1996). Ethnography, linguistics, narrative inequality: Toward an understanding of voice. London, UK: Taylor \& Francis.

Jiménez, R. T., García, G. E., \& Pearson, P. D. (1996). The reading strategies of bilingual Latina/o students who are successful English readers: Opportunities and obstacles. Reading Research Quarterly, 31(1), 90-112.

Kennedy, P. (2002). Learning cultures and learning styles: Myth-understandings about adult (Hong Kong) Chinese learners. International Journal of Lifelong Education, 21(5), 430-445.Available at: https://doi.org/10.1080/02601370210156745.

Kim, E. G. (2017). English medium instruction in Korean higher education: Challenges and future directions. In B. Fenton-Smith, P. Humphreys, \& I. Walkinshaw (Eds.), English Medium Instruction in Higher Education in Asia-Pacific (pp. 53-69). Cham, Switzerland: Springer International Publishing.

Krashen, S. D. (1982). Principles and practice in second language acquisition. Oxford, UK: Pergamon.

Lee, J. S., \& Lee, K. (2019). Perceptions of English as an international language by Korean English-major and non-English-major students. Journal of Multilingual and Multicultural Development, 4O(1), 76-89.

Liao, H.-C., \& Yang, C.-C. (2012). Teaching practice and cultural difference of an English as foreign language cassroom in Taiwan. English Language Teaching, 5(11), 151-160.Available at: https://doi.org/10.5539/elt.v5n11p151.

Pratt, D. D. (1992). Chinese conceptions of learning and teaching: A westerner's attempt at understanding. International Journal of Lifelong Education, $11(4)$, 301-319.Available at: https://doi.org/10.1080/0260137920110404.

Richards, J., \& Rodgers, T. (2001). Approaches and methods in language teaching. Cambridge, UK: Cambridge University Press.

San-Valero, P., Robles, A., Ruano, M., Martí, N., Cháfer, A., \& Badia, J. (2019). Workshops of innovation in chemical engineering to train communication skills in science and technology. Education for Chemical Engineers, 26, 114-121.Available at: https://doi.org/10.1016/j.ece.2018.07.001.

Savignon, S. J. (1987). Communicative language teaching. Theory Into Practice, 26(4), 235-242.

Savignon, S. J. (2002). Interpreting communicative language teaching: Contexts and concerns in teacher education. New Haven, CT: Yale University Press.

Sottie, C. A., Mfoafo-M'Carthy, M., \& Moasun, F. (2018). Graduate social work students' perceptions and attitude toward mental illness: implications for practice in developing countries. Social Work in Mental Health, 16(5), 540-555.Available at: https://doi.org/10.1080/15332985.2018.1448325.

Taguchi, T., Magid, M., \& Papi, M. (2009). The 12 motivational self system among Japanese, Chinese and Iranian learners of English: A comparative study. In Z. Dornyei \& E. Ushioda (Eds.), Motivation, language identity and the L2 self (pp. 66-97). Bristol, UK: Multilingual Matters.

Tweedie, M. G., \& Johnson, R. C. (2018). Listening instruction for ESP: Exploring nursing education where English is a lingua franca. Paper presented at the In International Perspectives on Teaching the Four Skills in ELT. 
Vygotsky, L. S. (1978). Mind in society: The development of higher psychological processes. (M. Cole, V. John-Steiner, S. Scribner, छ E. Souverman, eds.). Cambridge, MA: Harvard University Press.

Vygotsky, L. S. (1981). The genius of high mental functions. In J. Wertsch (Ed.), The concept of activity in Soviet psychology (pp. 144-188). Armonk, NY: Sharpe.

Wagner, R. K., Torgesen, J. K., \& Rashotte, C. A. (1994). Development of reading-related phonological processing abilities: New evidence of bidirectional causality from a latent variable longitudinal study. Developmental Psychology, 30(1), 73-87.Available at: https://doi.org/10.1037/0012-1649.30.1.73.

Weiner, L. (2012). The future of our schools: Teachers unions and social justice. Chicago, IL: Haymarket Books.

Weiner, L., \& Jerome, D. (2016). Urban teaching: The essentials (3rd ed.). New York, NY: Teachers College Press. 